\title{
Significance of Immune Checkpoint Inhibitors in Patients with Locally Advanced Non-Small Cell Lung Cancer Treated with Chemoradiotherapy Prior to the Approval of Durvalumab
}

Tomoya Fukui ( $\nabla$ tofukui@med.kitasato-u.ac.jp )

Kitasato University School of Medicine

Shinji Hosotani

Kitasato University School of Medicine

Itaru Soda

Kitasato University School of Medicine

Takahiro Ozawa

Kitasato University School of Medicine

Seiichiro Kusuhara

Kitasato University School of Medicine

Mikiko Kakegawa

Kitasato University School of Medicine

Masashi Kasajima

Kitasato University School of Medicine

Yasuhiro Hiyoshi

Kitasato University School of Medicine

Satoshi Igawa

Kitasato University School of Medicine

Masanori Yokoba

Kitasato University School of Allied Health Sciences

Hisashi Mitsufuji

Kitasato University School of Nursing

Masaru Kubota

Kitasato University School of Allied Health Sciences

Masato Katagiri

Kitasato University School of Allied Health Sciences

Jiichiro Sasaki

Kitasato University School of Medicine

Hiromichi Ishiyama

Kitasato University School of Medicine 


\section{Katsuhiko Naoki}

Kitasato University School of Medicine

\section{Research article}

Keywords: Non-small cell lung cancer, locally advanced, chemoradiotherapy, radiation pneumonitis, immune checkpoint inhibitor

Posted Date: October 18th, 2019

DOl: https://doi.org/10.21203/rs.2.16193/v1

License: (c) (i) This work is licensed under a Creative Commons Attribution 4.0 International License. Read Full License 


\section{Abstract}

Background: The standard treatment for patients with unresectable locally advanced (LA) non-small cell lung cancer (NSCLC) was chemoradiotherapy (CRT). Consolidation therapy with durvalumab, an antiprogrammed death ligand-1 antibody, after CRT demonstrated survival benefits and was approved in Japan in July 2018. The use of immune checkpoint inhibitors (ICls) is entering routine oncological practice, and we investigate the feasibility of concurrent CRT for LA-NSCLC patients based on the PACIFIC criteria.

Methods: We performed a retrospective study to evaluate the feasibility and efficacy of concurrent CRT prior to the approval of durvalumab. We assessed consecutive patients with LA-NSCLC treated with CRT between January 2012 and June 2018 in clinical practice, based on the PACIFIC criteria.

Results: We analyzed a total of 108 consecutive patients ( 81 males and 27 females) who received radical thoracic radiotherapy and concurrent platinum-based chemotherapy. Of those, 105 patients (97\%) completed the planned radiotherapy. Radiation pneumonitis was observed in 93 patients (85\%), with a median of 130 days (range: 41-317 days) from the initiation of radiation to the onset of the complication. Among the patients, 74 (69\%) were considered eligible for consolidation therapy with durvalumab. The overall response rate was $64 \%$, and the 2 -year survival rate was $63 \%$. Of the 82 patients who relapsed after CRT, 18 patients received treatment with an ICI in the course of treatment. Patients who received an $\mathrm{ICl}$ after relapse were associated with significantly better survival than those who did not receive an $\mathrm{ICl}(2$-year survival rate: $87 \%$ vs. $41 \%$, respectively; $\mathrm{p}=0.001)$.

Conclusion: Prior to the approval of durvalumab, the clinical application of ICls improved the outcome of patients with relapsed NSCLC after CRT for LA-NSCLC. The treatment strategy of ICI consolidation therapy for patients with LA-NSCLC and the management of radiation pneumonitis are challenges following the approval of durvalumab.

\section{Background}

The current standard treatment for unresectable locally advanced (LA) non-small cell lung cancer (NSCLC) is definitive concurrent chemoradiotherapy (CRT). The efficacy of thoracic radiotherapy (TRT) for LA-NSCLC was evaluated in 1968, when 800 patients with LA-NSCLC were treated with 40-50 Gy of TRT. The overall survival (OS) was significantly improved in the TRT group compared with the placebo group (4.6 vs. 3.7 months, respectively) [1]. In 1990, a combination of TRT with cisplatin plus vinblastine significantly prolonged survival compared with TRT alone (OS: 13.7 vs. 9.6 months, respectively; $p=$ 0.0066) [2], and CRT has been positioned as the standard of care for patients with LA-NSCLC [3-5]. In recent years, a clinical trial compared cisplatin plus pemetrexed with cisplatin plus etoposide for TRT 60$66 \mathrm{~Gy}$ as a combination chemotherapy regimen. However, the results did not show a significant improvement in OS (OS: 26.8 vs. 25.0 months, respectively; hazard ratio [HR]: 0.98; 95\% confidence interval [Cl]: $0.79-1.20 ; p=0.831)[6]$. 
In the past 20 years, there has been no improvements in outcome (2-year survival rate: $40-60 \%)[3,6-8]$. However, in the PACIFIC Trial, concurrent CRT followed by consolidation therapy with durvalumab resulted in a significant prolongation of progression-free survival (PFS) compared with placebo (PFS: 17.2 vs. 5.6 months, respectively; stratified HR, $0.51 ; 95 \% \mathrm{Cl}: 0.41-0.63)$ and the OS rate at 24 months $(66.3 \%$ vs. $55.6 \%$, respectively; stratified HR: $0.68 ; 99.73 \% \mathrm{Cl}$ : 0.47-0.997) $[9,10]$. Based on the results of this study, durvalumab was approved in Japan in July 2018 as consolidation therapy after CRT. The main inclusion criteria in the PACIFIC Trial were (1) patients with stage III, unresectable NSCLC; (2) patients who had received two or more cycles of platinum-based chemotherapy concurrently with TRT (54-66 Gy), in which the mean lung dose was $<20 \mathrm{~Gy}$, the V20 (the volume of lung parenchyma that received $\geq 20 \mathrm{~Gy}$ ) was $<35 \%$, or both; (3) absence of disease progression after CRT; (4) age $\geq 18$ years; (5) a World Health Organization performance status (PS) of $0-1 ;(6)$ an estimated life expectancy $\geq 12$ weeks; and (7) completion of the last radiation dose within 1-42 days prior to randomization of consolidation therapy with durvalumab. Key exclusion criteria were active or previous autoimmune disease (within the previous 2 years) or a history of primary immunodeficiency; evidence of uncontrolled, concurrent illness, or ongoing or active infections; unresolved toxic effects of grade $\geq 2$ (according to the Common Terminology Criteria for Adverse Events [CTCAE]); and grade $\geq 2$ pneumonitis from previous CRT [9]. It is thought that the proportion of patients meeting the criteria of the PACIFIC Trial who should receive consolidation therapy with durvalumab is limited in clinical practice. In addition, new challenges in the management of side effects, such as radiation pneumonitis, have arisen.

Checkpoint immunotherapy has demonstrated high efficacy in numerous types of cancer [11, 12], including NSCLC. Prior to the approval of durvalumab, nivolumab [13, 14] (December 2015), pembrolizumab [15] (December 2016), and atezolizumab [16] (January 2018) were approved in Japan as the second or subsequent line of therapy against advanced or recurrent NSCLC. Moreover, pembrolizumab monotherapy [17] became available as the initial chemotherapy for programmed death ligand-1-positive advanced NSCLC in December 2016. Furthermore, in December 2018, the use of pembrolizumab $[18,19]$ or atezolizumab $[20]$ plus chemotherapy was expanded to the first-line treatment of metastatic NSCLC. The use of immune checkpoint inhibitors (ICls) showed durable clinical benefit and long-term remissions in some patients [21-23], and has altered the standard of care for patients with metastatic NSCLC.

Now that the clinical issues related to the use of ICI for LA-NSCLC patients in clinical practice are expected, it is considered important to evaluate patients who are effective in CRT. To investigate the feasibility of concurrent CRT for LA-NSCLC patients based on the PACIFIC criteria, while ICls have been used widely for the treatment of advanced-stage disease, we retrospectively assessed consecutive patients with LA-NSCLC treated with concurrent CRT (prior to the approval of durvalumab) in clinical practice to investigate the feasibility of this regimen.

\section{Methods}




\section{Study patients and collection of clinical data}

This retrospective study included 108 consecutive patients with LA-NSCLC treated with CRT at the Kitasato University Hospital (Kanagawa, Japan) between January 2012 and June 2018. All patients underwent computed tomography (CT) for three-dimensional conformal TRT, and received concurrent TRT in combination with platinum-based chemotherapy. We examined the clinical records (e.g., date of diagnosis, sex, smoking status, tumor-node-metastasis staging, histology, mutational status, PS, course of treatment, adverse events [AEs] including radiation pneumonitis, and survival time) of each patient.

\section{Evaluation of response and survival}

Tumor response was classified in accordance with the Response Evaluation Criteria for Solid Tumors (version 1.1), based on the results of a complete medical history, physical examination, chest X-ray examination, CT of the chest and abdomen, and other procedures (i.e., magnetic resonance imaging of the brain, positron emission tomography-CT, and bone scintigraphy). Survival was defined as the time from the initiation of TRT to the date of documentation of treatment failure (death or disease progression) or the date of censoring at the final follow-up examination (data cutoff: June 30, 2018; follow-up time: median 20.5 months; range: 0.9-79.5 months). Patients with LA-NSCLC were classified according to the initiation of TRT from January 2012 to June 2015 (2012-2015 cohort) and from July 2015 to June 2018 (2015-2018 cohort) to compare the short-term survival between two recent cohorts.

\section{Statistical analysis}

All survival analyses were performed using the Kaplan-Meier method. Survival rates between subgroups were compared using the log-rank test. The Cox proportional hazards model was used to conduct univariate and multivariate analyses to identify prognostic factors. The multivariate analysis was performed with adjustments for covariates, including significant clinical factors identified in the univariate analyses. All analyses were performed using the SPSS software program, version 25.0 (SPSS, IBM Corp., Armonk, NY, USA).

This study was approved by the Kitasato University Medical Ethics Organization (B18-216), which waived the requirement for patient informed consent due to the retrospective nature of the study.

\section{Results}

\section{Patient characteristics}

In total, 108 patients were treated with concurrent CRT combined with platinum-based chemotherapy. Of these, 52 patients were treated between January 2012 and June 2015 and 56 patients were treated 
between July 2015 and June 2018 (Supplemental Figure 1A). The characteristics of the patients included in this study are shown in Table 1 . The median age was 65 years (range: $36-76$ years), 81 of the patients (75\%) were male, and only 11 patients (10\%) were non-smokers. Notably, 46 patients (43\%) had adenocarcinoma, including two patients with epidermal growth factor receptor mutations, four patients with anaplastic lymphoma kinase rearrangements, and one patient with ROS1 mutation. In addition, 38 patients (35\%) had squamous cell carcinoma.

We confirmed the patients eligible to receive consolidation therapy with durvalumab based on the criteria of the PACIFIC Trial [9]. In our cohort, 74 patients (69\%) who received concurrent CRT met these criteria (Supplemental Figure 1B, Supplemental Table 1). Reasons for ineligibility were AEs of grade $\geq 2$ after CRT $(n=9)$, disease progression $(n=8)$, grade 2 radiation pneumonitis $(n=6)$, receiving only one cycle of chemotherapy $(n=5)$, interstitial pneumonia combined $(n=3)$, and other complications (e.g., rheumatoid arthritis, colon cancer, and angina) $(n=3)$.

\section{Chemoradiotherapy for patients with LA-NSCLC in clinical practice}

All patients received radical TRT using a three-dimensional planning system with a median 60-Gy dose (range: 10-66 Gy) and concurrent platinum-based chemotherapy. The chemotherapy regimens used most commonly were cisplatin plus vinorelbine in 83 patients (77\%) and weekly carboplatin plus paclitaxel in 19 patients (18\%). Notably, 79 patients (73\%) received one or two cycles of consolidation chemotherapy with the same regimen. Of the 82 patients who relapsed after CRT, 43 patients $(52 \%)$ received cytotoxic drugs, 18 patients (22\%) received treatment with an $\mathrm{ICl}$, and seven patients $(9 \%)$ received targeted tyrosine kinase inhibitors (TKI) in the course of treatment. Treatment details are shown in Table 2.

\section{Safety of chemoradiotherapy}

A total of 105 patients (97\%) completed the planned radiotherapy. The reasons for discontinuing radiotherapy were hemoptysis at $10 \mathrm{~Gy}$, esophageal tracheal fistula at $32 \mathrm{~Gy}$, and paralysis due to spinal cord invasion of the primary lesion at $50 \mathrm{~Gy}$. Radiation pneumonitis was observed in 93 patients (85\%), with a median of 130 days (range: 41-317 days) from the initiation of radiation to the onset of the complication. Among these, 63 patients (58\%) developed grade 1 radiation pneumonitis, while 30 patients $(28 \%)$ developed grade $2-3$ radiation pneumonitis, including 27 patients $(25 \%)$ who required the administration of steroids (Table 3). High levels of V20 (\%), V5 (\%), and mean lung dose (Gy) for TRT were related to grade 2-3 pneumonitis. However, the pretreatment level of $K L-6$, a marker of interstitial pneumonia, was not associated with the severity of radiation pneumonitis (Supplemental Figure 2). Nine patients experienced non-hematological toxic effects of CTCAE grade $\geq 2$ from previous CRT, which 
included anorexia $(n=4)$, febrile neutropenia $(n=1)$, numbness $(n=1)$, tracheoesophageal fistula $(n=1)$, pyothorax $(n=1)$, and sepsis $(n=1)$.

\section{Treatment outcomes in patients with LA-NSCLC}

The overall response rate to CRT was $64 \%$ (Table 3 ) and the PFS was 10.3 months ( $95 \%$ Cl: $8.4-12.2$ ) (Figure 1A). The OS was 41.8 months (95\% Cl: 20.1-63.5), with 2- and 5-year survival rates of $63 \%$ and $41 \%$, respectively (Figure 1B). Although the PFS was not significantly different between the two groups (Figure 1C), the OS was significantly better in the 2015-2018 cohort than in the 2012-2015 cohort, with a 2-year survival rate of $75 \%$ vs. $54 \%$, respectively $(p=0.042)$ (Figure 1D). During the period of this study, the TRT planning method employed in our hospital was not changed. Therefore, we analyzed subsequent chemotherapy for patients with recurrent disease after CRT to assess the difference in OS. Of the 82 patients who relapsed after CRT, 18 patients received treatment with an ICI (i.e., nivolumab [n = 14], pembrolizumab [ $=3]$, and atezolizumab [ $=1]$ ) (Table 2). Among the LA-NSCLC patients who relapsed after CRT, the OS of those treated with ICls was superior to that of patients not treated with an ICl. However, it was not superior to that of patients who received targeted treatment with a TKI (Figure 2, Supplemental Table 2).

The univariate analyses of the clinical characteristics revealed that PS ( 2 vs. $0-1 ; p=0.003$ ), treatment period (2015-2018 vs. 2012-2015; $p=0.046)$, administration of ICls after recurrence (received vs. not received; $p=0.003$ ), the PACIFIC criteria (eligible vs. ineligible; $p=0.028$ ), and radiation pneumonitis (grade $1-3$ vs. grade $0 ; p=0.037$ ) were significantly associated with OS. The multivariate analyses, adjusted for these cofactors, revealed that treatment with an ICl after the patients relapsed after CRT (HR: 0.20; $95 \% \mathrm{Cl}: 0.07-0.57 ; p=0.003$ ) was a favorable prognostic factor (Table 4).

\section{Discussion}

This retrospective study evaluated the outcome of concurrent CRT with platinum-based chemotherapy. The results summarize the current status with regard to the efficacy and safety for the treatment of patients with LA-NSCLC in clinical practice prior to the approval of durvalumab. Based on clinical trials involving patients with unresectable LA-NSCLC, the treatment outcome has not improved for more than a decade, although several treatment strategies have been evaluated in clinical trials [3-7, 24-27]. The efficacy of consolidation therapy with cytotoxic drugs after CRT also failed to demonstrate an improved prognosis $[8,28]$. The PACIFIC Trial evaluated consolidation therapy with durvalumab after concurrent CRT for the treatment of patients with unresectable LA-NSCLC, yielding clinically meaningful results [9, 29]. The results of this trial revealed that durvalumab significantly improved PFS versus placebo (17.2 vs. 5.6 months, respectively; HR: $0.51 ; 95 \% \mathrm{Cl}: 0.41-0.63$ ) and OS (stratified HR: $0.68 ; 99.73 \% \mathrm{Cl}: 0.47-0.997$; $p=0.0025)$. The 2-year survival rates in the durvalumab and placebo groups were $66.3 \%$ (95\% Cl: $61.7-$ 70.4) and 55.6\% (95\% Cl: 48.9-61.8), respectively $(p=0.005)$ [29]. These findings indicated that durvalumab is an effective treatment option for patients with LA-NSCLC who meet the PACIFIC criteria. 
However, it is necessary to accumulate additional data regarding the identification of patients who can receive consolidation therapy with durvalumab in the clinical setting. In our retrospective study, concurrent CRT for the treatment of unresectable LA-NSCLC was effective in clinical practice, with acceptable toxicity, prior to the approval of durvalumab. The median OS was 41.8 months (95\% Cl: $20.1-$ $65.5)$, the 2 -year survival was $63 \%$, and the 5 -year survival was $41 \%$.

Prior to their use in the treatment of LA-NSCLC, ICls were approved for metastatic or advanced NSCLC [13-20], and have been used widely in daily practice owing their safety and effectiveness. In previously treated patients with advanced NSCLC, the 3-year survival rate with nivolumab versus docetaxel was $17 \%$ (95\% Cl: $14-21)$ versus $8 \%$ (95\% Cl: 6-11), respectively [23]. In a pooled population of relapsed patients with NSCLC (CHECKMATE 017 and 057), the 4-year updated survival rate with nivolumab was 14\% (95\% Cl: 11-17) [30]. In a phase I study of pembrolizumab (KEYNOTE-001), the 3-year survival rate was $26.4 \%$ (95\% Cl: 14.3-40.1) for treatment-naive patients and 19.0\% (95\% Cl: 15.0-23.4) for previously treated patients [31]. In a subgroup analysis of the KEYNOTE-001 Trial, the efficacy of ICls after radiotherapy was investigated in 38 of 97 patients with metastatic NSCLC who received extracranial radiotherapy prior to pembrolizumab. The results showed that treatment with an $\mathrm{ICl}$ was associated with significantly longer PFS (median: 6.3 [95\% Cl: $2.1-10.4]$ vs. 2.0 months [95\% Cl: 1.8-2.1], respectively; HR: 0.50 [95\% Cl: 0.30-0.84]) and OS (median: 11.6 [95\% Cl: 6.5-20.5] vs. 5.3 months [95\% Cl: 3.0-8.5], respectively; HR: 0.59 [95\% Cl: 0.36-0.96]) compared with those reported in patients who did not receive prior extracranial radiotherapy [32]. In this study, patients with LA-NSCLC who relapsed after CRT and were subsequently treated with ICls were associated with better prognosis than those who did not receive treatment with ICls (2-year survival rate: $87 \%$ vs. $41 \%$, respectively; $p=0.001$ ). There is an increasing body of preclinical and clinical data regarding the radiotherapy-induced immunomodulatory effects in the local tumor microenvironment, supporting the combination strategy [33-35]. Radiotherapy modifies the tumor microenvironment, including enhanced antigen presentation, and the upregulation of tumor programmed death ligand-1 and major histocompatibility complex class I expression [33, 36-39]. In addition to the local effects of irradiation at the tumor site, radiotherapy can also mediate an abscopal effect, which is linked to an immune-mediated mechanism [40-42]. The combination of radiotherapy and immunotherapy is considered an effective treatment strategy. In our study, the use of ICI for recurrence after CRT was a favorite prognostic factor for the patients with LA-NSCLC.

In the PACIFIC Trial, the eligibility criteria were stringent compared with those in routine clinical practice. Thus, 74 of the 108 patients (69\%) who received concurrent CRT with platinum-based chemotherapy in our study met the PACIFIC criteria in the clinical setting. Regarding the schedule of the PACIFIC Trial, the patients with LA-NSCLC were randomized for consolidation therapy with durvalumab within 42 days after the completion of TRT based on the concept of immunomodulation through radiotherapy. Furthermore, in the subgroup analysis, the therapeutic effects of early initiation (i.e., within 14 days) were high, and the early use of an ICl was expected. On the other hand, even in relapsed patients with advanced or metastatic NSCLC, previous radiotherapy may increase the effect of treatment with an ICI [32], although the mechanism involved in this process is currently unclear. The optimal treatment method, namely, the timing and duration of immunotherapy combined with radiotherapy, should be verified. Moreover, 
appropriate patient selection should be performed using reliable and predictive biomarkers, cytotoxic Tcell infiltration and functionality, status of major histocompatibility complex expression, neoantigen burden, metabolic status, and general immune status factors (e.g., neutrophil-to-lymphocyte ratio) [43, 44].

Radiation pneumonitis occurs frequently after TRT [45], and is characterized by clinically significant toxicity. In our study, radiation pneumonitis was found in approximately $90 \%$ of patients. However, its severity was mild/moderate in the majority of cases (CTCAE grade 1: $58 \%$; grade 2: $26 \%$; and grade 3 : $1 \%)$, and the complication was manageable according to the appropriate radiotherapy plan. In the PACIFIC Trial, the incidence of AEs of any cause was similar in the durvalumab group versus the placebo group for AEs of any grade ( $97 \%$ vs. $95 \%$, respectively), grade $3-4$ AEs ( $30 \%$ vs. $26 \%$, respectively), and serious AEs ( $29 \%$ vs. $23 \%$, respectively) [9]. The most common grade $3-4$ AEs were pneumonia ( $4 \%$ vs. $4 \%$, respectively) and pneumonitis (3\% vs. $3 \%$, respectively). In several retrospective analyses, patients with advanced NSCLC who had received TRT and nivolumab exhibited a higher incidence of drug-induced interstitial lung disease than those without TRT $[46,47]$. In the future, real-world data will also be important in selecting the appropriate patients and establishing optimal treatment strategies (e.g., radiation dose, fractionation, field volume, schedule of treatment with ICls, and treatment period) to combine radiotherapy with ICls. Furthermore, elucidation of the effects of immune activation by ICls on radiation pneumonitis is also required.

This study had certain limitations. First, this was a retrospective study conducted at a single institution with a small sample size; hence, the results cannot be considered definitive. Second, the current study included patients with LA-SCLC who could receive TRT concurrent with platinum-based chemotherapy; thus, it does not represent the overall status of stage III LA-NSCLC in clinical practice. Third, ICls are considered an important treatment option for patients with LA-NSCLC in whom TRT is indicated.

Nevertheless, this study did not provide clear data regarding the treatment methods, such as timing and duration of use.

\section{Conclusion}

This retrospective study demonstrated the prognostic improvement in patients with LA-NSCLC treated with concurrent CRT, followed by treatment with ICls in the clinical setting even before the approval of durvalumab. The occurrence of radiation pneumonitis and drug-induced interstitial lung disease poses a challenge to this treatment strategy. Therefore, appropriate patient selection, based on clinical factors and predictive markers, should be considered for the development of optimal treatment strategies.

\section{Abbreviation}

LA: locally advanced, NSCLC: non-small cell lung cancer, CRT: chemoradiotherapy, TRT: thoracic radiotherapy, OS: overall survival, HR: hazard ratio, Cl: confidence interval, PFS: progression-free survival, PS: performance status, CTCAE: Common Terminology Criteria for Adverse Events, ICl: immune 
checkpoint inhibitor, CT: computed tomography, AE: adverse event, EGFR: epidermal growth factor receptor, ALK: anaplastic lymphoma kinase, TKI: tyrosine kinase inhibitor

\section{Declarations}

\section{Competing interests}

The authors stated that they have no conflicts of interest to declare.

\section{Authors' contributions}

TF and KN developed the conceptual study. TF, SH, TO, SK, MK, MK, YH, SI, MY, HM, MK and JS collected the clinical data and managed the database. IS and HI collected the data of radiotherapy. TF performed statistical analysis and drafted the manuscript. All authors reviewed and approved the manuscript.

\section{Authors' information}

${ }^{1}$ Department of Respiratory Medicine, Kitasato University School of Medicine, 1-15-1 Kitasato, Minamiku, Sagamihara, Kanagawa 252-0374, JAPAN

2 Department of Radiology and Radiation Oncology, Kitasato University School of Medicine, 1-15-1 Kitasato, Minami-ku, Sagamihara, Kanagawa 252-0374, JAPAN

${ }^{3}$ Department of Medical Laboratory, Kitasato University School of Allied Health Sciences, 1-15-1 Kitasato, Minami-ku, Sagamihara, Kanagawa 252-0374, JAPAN

${ }^{4}$ Fundamental Nursing, Kitasato University School of Nursing, 1-15-1 Kitasato, Minami-ku, Sagamihara, Kanagawa 252-0374, JAPAN

${ }^{5}$ Research and Development Center for New Medical Frontiers, Kitasato University School of Medicine, 1-15-1 Kitasato, Minami-ku, Sagamihara, Kanagawa 252-0374, JAPAN

\section{Acknowledgements}

The authors would like to thank Enago (www.enago.jp) for the English language review.

\section{References}

1.Roswit B, Patno ME, Rapp R, Veinbergs A, Feder B, Stuhlbarg J, Reid CB: The survival of patients with inoperable lung cancer: a large-scale randomized study of radiation therapy versus placebo. Radiology 1968, 90(4):688-697. 
2.Dillman RO, Seagren SL, Propert KJ, Guerra J, Eaton WL, Perry MC, Carey RW, Frei EF, 3rd, Green MR: $A$ randomized trial of induction chemotherapy plus high-dose radiation versus radiation alone in stage III non-small-cell lung cancer. The New England journal of medicine 1990, 323(14):940-945.

3.Auperin A, Le Pechoux C, Rolland E, Curran WJ, Furuse K, Fournel P, Belderbos J, Clamon G, Ulutin HC, Paulus $\mathrm{R}$ et al: Meta-analysis of concomitant versus sequential radiochemotherapy in locally advanced non-small-cell lung cancer. Journal of clinical oncology: official journal of the American Society of Clinical Oncology 2010, 28(13):2181-2190.

4.Yamamoto N, Nakagawa K, Nishimura Y, Tsujino K, Satouchi M, Kudo S, Hida T, Kawahara M, Takeda K, Katakami $\mathrm{N}$ et al: Phase III study comparing second-and third-generation regimens with concurrent thoracic radiotherapy in patients with unresectable stage III non-small-cell lung cancer: West Japan Thoracic Oncology Group WJTOG0105. Journal of clinical oncology: official journal of the American Society of Clinical Oncology 2010, 28(23):3739-3745.

5.Segawa Y, Kiura K, Takigawa N, Kamei H, Harita S, Hiraki S, Watanabe Y, Sugimoto K, Shibayama T, Yonei T et al: Phase III trial comparing docetaxel and cisplatin combination chemotherapy with mitomycin, vindesine, and cisplatin combination chemotherapy with concurrent thoracic radiotherapy in locally advanced non-small-cell lung cancer: OLCSG 0007. Journal of clinical oncology: official journal of the American Society of Clinical Oncology 2010, 28(20):3299-3306.

6.Senan S, Brade A, Wang LH, Vansteenkiste J, Dakhil S, Biesma B, Martinez Aguillo M, Aerts J, Govindan R, Rubio-Viqueira B et al: PROCLAIM: Randomized Phase III Trial of Pemetrexed-Cisplatin or EtoposideCisplatin Plus Thoracic Radiation Therapy Followed by Consolidation Chemotherapy in Locally Advanced Nonsquamous Non-Small-Cell Lung Cancer. Journal of clinical oncology: official journal of the American Society of Clinical Oncology 2016, 34(9):953-962.

7.Furuse K, Fukuoka M, Kawahara M, Nishikawa H, Takada Y, Kudoh S, Katagami N, Ariyoshi Y: Phase III study of concurrent versus sequential thoracic radiotherapy in combination with mitomycin, vindesine, and cisplatin in unresectable stage III non-small-cell lung cancer. Journal of clinical oncology: official journal of the American Society of Clinical Oncology 1999, 17(9):2692-2699.

8.Tsujino K, Kurata T, Yamamoto S, Kawaguchi T, Kubo A, Isa S, Hasegawa Y, Ou SH, Takada M, Ando M: Is consolidation chemotherapy after concurrent chemo-radiotherapy beneficial for patients with locally advanced non-small-cell lung cancer? A pooled analysis of the literature. Journal of thoracic oncology: official publication of the International Association for the Study of Lung Cancer 2013, 8(9):1181-1189.

9.Antonia SJ, Villegas A, Daniel D, Vicente D, Murakami S, Hui R, Yokoi T, Chiappori A, Lee KH, de Wit M et al: Durvalumab after Chemoradiotherapy in Stage III Non-Small-Cell Lung Cancer. The New England journal of medicine 2017, 377(20):1919-1929.

10.Antonia SJ, Villegas A, Daniel D, Vicente D, Murakami S, Hui R, Kurata T, Chiappori A, Lee KH, de Wit M et al: Overall Survival with Durvalumab after Chemoradiotherapy in Stage III NSCLC. The New England 
journal of medicine 2018.

11.Wang X, Bao Z, Zhang X, Li F, Lai T, Cao C, Chen Z, Li W, Shen H, Ying S: Effectiveness and safety of $P D-1 / P D-L 1$ inhibitors in the treatment of solid tumors: a systematic review and meta-analysis.

Oncotarget 2017, 8(35):59901-59914.

12.Salama AK, Moschos SJ: Next steps in immuno-oncology: enhancing antitumor effects through appropriate patient selection and rationally designed combination strategies. Annals of oncology: official journal of the European Society for Medical Oncology / ESMO 2017, 28(1):57-74.

13.Brahmer J, Reckamp KL, Baas P, Crino L, Eberhardt WE, Poddubskaya E, Antonia S, Pluzanski A, Vokes EE, Holgado E et al: Nivolumab versus Docetaxel in Advanced Squamous-Cell Non-Small-Cell Lung Cancer. The New England journal of medicine 2015, 373(2):123-135.

14.Borghaei H, Paz-Ares L, Horn L, Spigel DR, Steins M, Ready NE, Chow LQ, Vokes EE, Felip E, Holgado E et al: Nivolumab versus Docetaxel in Advanced Nonsquamous Non-Small-Cell Lung Cancer. The New England journal of medicine 2015, 373(17):1627-1639.

15. Herbst RS, Baas P, Kim DW, Felip E, Perez-Gracia JL, Han JY, Molina J, Kim JH, Arvis CD, Ahn MJ et al: Pembrolizumab versus docetaxel for previously treated, PD-L 1-positive, advanced non-small-cell lung cancer (KEYNOTE-010): a randomised controlled trial. Lancet 2016, 387(10027):1540-1550.

16.Rittmeyer A, Barlesi F, Waterkamp D, Park K, Ciardiello F, von Pawel J, Gadgeel SM, Hida T, Kowalski DM, Dols MC et al: Atezolizumab versus docetaxel in patients with previously treated non-small-cell lung cancer (OAK): a phase 3, open-label, multicentre randomised controlled trial. Lancet 2017, 389(10066):255-265.

17.Reck M, Rodriguez-Abreu D, Robinson AG, Hui R, Csoszi T, Fulop A, Gottfried M, Peled N, Tafreshi A, Cuffe S et al: Pembrolizumab versus Chemotherapy for PD-L 1-Positive Non-Small-Cell Lung Cancer. The New England journal of medicine 2016, 375(19):1823-1833.

18.Gandhi L, Rodriguez-Abreu D, Gadgeel S, Esteban E, Felip E, De Angelis F, Domine M, Clingan P, Hochmair MJ, Powell SF et al: Pembrolizumab plus Chemotherapy in Metastatic Non-Small-Cell Lung Cancer. The New England journal of medicine 2018, 378(22):2078-2092.

19.Paz-Ares L, Luft A, Vicente D, Tafreshi A, Gumus M, Mazieres J, Hermes B, Cay Senler F, Csoszi T, Fulop A et al: Pembrolizumab plus Chemotherapy for Squamous Non-Small-Cell Lung Cancer. The New England journal of medicine 2018, 379(21):2040-2051.

20.Socinski MA, Jotte RM, Cappuzzo F, Orlandi F, Stroyakovskiy D, Nogami N, Rodriguez-Abreu D, MoroSibilot D, Thomas CA, Barlesi F et al: Atezolizumab for First-Line Treatment of Metastatic Nonsquamous NSCLC. The New England journal of medicine 2018, 378(24):2288-2301. 
21.Horn L, Spigel DR, Vokes EE, Holgado E, Ready N, Steins M, Poddubskaya E, Borghaei H, Felip E, PazAres L et al: Nivolumab Versus Docetaxel in Previously Treated Patients With Advanced Non-Small-Cell Lung Cancer: Two-Year Outcomes From Two Randomized, Open-Label, Phase III Trials (CheckMate 017 and CheckMate 057). Journal of clinical oncology: official journal of the American Society of Clinical Oncology 2017, 35(35):3924-3933.

22.Gettinger S, Horn L, Jackman D, Spigel D, Antonia S, Hellmann M, Powderly J, Heist R, Sequist LV, Smith DC et al: Five-Year Follow-Up of Nivolumab in Previously Treated Advanced Non-Small-Cell Lung Cancer: Results From the CA209-003 Study. Journal of clinical oncology: official journal of the American Society of Clinical Oncology 2018, 36(17):1675-1684.

23.Vokes EE, Ready N, Felip E, Horn L, Burgio MA, Antonia SJ, Aren Frontera O, Gettinger S, Holgado E, Spigel D et al: Nivolumab versus docetaxel in previously treated advanced non-small-cell lung cancer (CheckMate 017 and CheckMate 057): 3-year update and outcomes in patients with liver metastases. Annals of oncology: official journal of the European Society for Medical Oncology / ESMO 2018, 29(4):959-965.

24.Cheema PK, Rothenstein J, Melosky B, Brade A, Hirsh V: Perspectives on treatment advances for stage III locally advanced unresectable non-small-cell lung cancer. Current oncology (Toronto, Ont) 2019, 26(1):37-42.

25.Bradley JD, Paulus R, Komaki R, Masters G, Blumenschein G, Schild S, Bogart J, Hu C, Forster K, Magliocco A et al: Standard-dose versus high-dose conformal radiotherapy with concurrent and consolidation carboplatin plus paclitaxel with or without cetuximab for patients with stage IIIA or IIIB nonsmall-cell lung cancer (RTOG 0617): a randomised, two-by-two factorial phase 3 study. The Lancet Oncology 2015, 16(2):187-199.

26.Oh IJ, Kim KS, Kim YC, Ban HJ, Kwon YS, Kim YI, Lim SC, Chung WK, Nam TK, Song JY et al: A phase III concurrent chemoradiotherapy trial with cisplatin and paclitaxel or docetaxel or gemcitabine in unresectable non-small cell lung cancer: KASLC 0401. Cancer chemotherapy and pharmacology 2013, 72(6):1247-1254.

27.Liang J, Bi N, Wu S, Chen M, Lv C, Zhao L, Shi A, Jiang W, Xu Y, Zhou Z et al: Etoposide and cisplatin versus paclitaxel and carboplatin with concurrent thoracic radiotherapy in unresectable stage III nonsmall cell lung cancer: a multicenter randomized phase III trial. Annals of oncology: official journal of the European Society for Medical Oncology / ESMO 2017, 28(4):777-783.

28.Hanna N, Neubauer M, Yiannoutsos C, McGarry R, Arseneau J, Ansari R, Reynolds C, Govindan R, Melnyk A, Fisher W et al: Phase III study of cisplatin, etoposide, and concurrent chest radiation with or without consolidation docetaxel in patients with inoperable stage III non-small-cell lung cancer: the Hoosier Oncology Group and U.S. Oncology. Journal of clinical oncology: official journal of the American Society of Clinical Oncology 2008, 26(35):5755-5760. 
29.Antonia SJ, Villegas A, Daniel D, Vicente D, Murakami S, Hui R, Kurata T, Chiappori A, Lee KH, de Wit M et al: Overall Survival with Durvalumab after Chemoradiotherapy in Stage III NSCLC. The New England journal of medicine 2018, 379(24):2342-2350.

30.Antonia SJ, Borghaei H, Ramalingam SS, Horn L, De Castro Carpeno J, Pluzanski A, Burgio MA, Garassino M, Chow LQM, Gettinger $S$ et al: Four-year survival with nivolumab in patients with previously treated advanced non-small-cell lung cancer: a pooled analysis. The Lancet Oncology 2019.

31.LeighI NB, Hellmann MD, Hui R, Carcereny E, Felip E, Ahn MJ, Eder JP, Balmanoukian AS, Aggarwal C, Horn L et al: Pembrolizumab in patients with advanced non-small-cell lung cancer (KEYNOTE-001): 3year results from an open-label, phase 1 study. The Lancet Respiratory medicine 2019, 7(4):347-357.

32.Shaverdian N, Lisberg AE, Bornazyan K, Veruttipong D, Goldman JW, Formenti SC, Garon EB, Lee P: Previous radiotherapy and the clinical activity and toxicity of pembrolizumab in the treatment of nonsmall-cell lung cancer: a secondary analysis of the KEYNOTE-001 phase 1 trial. The Lancet Oncology 2017, 18(7):895-903.

33.Ko EC, Raben D, Formenti SC: The Integration of Radiotherapy with Immunotherapy for the Treatment of Non-Small Cell Lung Cancer. Clinical cancer research: an official journal of the American Association for Cancer Research 2018, 24(23):5792-5806.

34.Kordbacheh T, Honeychurch J, Blackhall F, Faivre-Finn C, Illidge T: Radiotherapy and anti-PD-1/PD-L1 combinations in lung cancer: building better translational research platforms. Annals of oncology: official journal of the European Society for Medical Oncology / ESMO 2018, 29(2):301-310.

35.Filippi AR, Di Muzio J, Badellino S, Mantovani C, Ricardi U: Locally-advanced non-small cell lung cancer: shall immunotherapy be a new chance? Journal of thoracic disease 2018, 10(Suppl 13):S1461s1467.

36.Deng L, Liang H, Burnette B, Beckett M, Darga T, Weichselbaum RR, Fu YX: Irradiation and anti-PD-L1 treatment synergistically promote antitumor immunity in mice. The Journal of clinical investigation 2014, 124(2):687-695.

37.Dovedi SJ, Cheadle EJ, Popple AL, Poon E, Morrow M, Stewart R, Yusko EC, Sanders CM, Vignali M, Emerson RO et al: Fractionated Radiation Therapy Stimulates Antitumor Immunity Mediated by Both Resident and Infiltrating Polyclonal T-cell Populations when Combined with PD-1 Blockade. Clinical cancer research: an official journal of the American Association for Cancer Research 2017, 23(18):55145526.

38.Yoneda K, Kuwata T, Kanayama M, Mori M, Kawanami T, Yatera K, Ohguri T, Hisaoka M, Nakayama T, Tanaka F: Alteration in tumoural PD-L 1 expression and stromal CD8-positive tumour-infiltrating lymphocytes after concurrent chemo-radiotherapy for non-small cell lung cancer. Br J Cancer 2019. 
39.Daly ME, Monjazeb AM, Kelly K: Clinical Trials Integrating Immunotherapy and Radiation for NonSmall-Cell Lung Cancer. Journal of thoracic oncology: official publication of the International Association for the Study of Lung Cancer 2015, 10(12):1685-1693.

40.Demaria S, Ng B, Devitt ML, Babb JS, Kawashima N, Liebes L, Formenti SC: Ionizing radiation inhibition of distant untreated tumors (abscopal effect) is immune mediated. International journal of radiation oncology, biology, physics 2004, 58(3):862-870.

41.Grass GD, Krishna N, Kim S: The immune mechanisms of abscopal effect in radiation therapy. Current problems in cancer 2016, 40(1):10-24.

42.Ng J, Dai T: Radiation therapy and the abscopal effect: a concept comes of age. Annals of translational medicine 2016, 4(6):118.

43.Blank CU, Haanen JB, Ribas A, Schumacher TN: CANCER IMMUNOLOGY. The "cancer immunogram". Science 2016, 352(6286):658-660.

44.Fukui T, Okuma Y, Nakahara Y, Otani S, Igawa S, Katagiri M, Mitsufuji $\mathrm{H}$, Kubota $\mathrm{M}$, Hiyoshi $\mathrm{Y}$, Ishihara $\mathrm{M}$ et al: Activity of Nivolumab and Utility of Neutrophil-to-Lymphocyte Ratio as a Predictive Biomarker for Advanced Non-Small-Cell Lung Cancer: A Prospective Observational Study. Clin Lung Cancer 2019, 20(3):208-214.e202.

45.Simone CB, 2nd: Thoracic Radiation Normal Tissue Injury. Seminars in radiation oncology 2017, 27(4):370-377.

46.Kataoka Y, Ebi N, Fujimoto D, Hara S, Hirano K, Narabayashi T, Tanaka T, Tomii K, Yoshioka H: Prior radiotherapy does not predict nivolumab response in non-small-cell lung cancer: a retrospective cohort study. Annals of oncology: official journal of the European Society for Medical Oncology / ESMO 2017, 28(6):1402.

47.Tamiya A, Tamiya M, Nakahama K, Taniguchi Y, Shiroyama T, Isa SI, Inoue T, Okishio K, Nishino K, Kumagai T et al: Correlation of Radiation Pneumonitis History Before Nivolumab with Onset of Interstitial Lung Disease and Progression-free Survival of Patients with Pre-treated Advanced Non-small Cell Lung Cancer. Anticancer research 2017, 37(9):5199-5205.

\section{Tables}

Table 1. Characteristics of the patients in this study $(n=108)$ 


\begin{tabular}{|c|c|c|c|c|c|c|}
\hline & \multicolumn{2}{|c|}{ All } & \multicolumn{2}{|c|}{$2012 / 1-2015 / 6$} & \multicolumn{2}{|c|}{$62015 / 7-2018 / 6$} \\
\hline & No. & $\%$ & No. & $\%$ & No. & $\%$ \\
\hline Patients, $n$ & 108 & $(100)$ & 52 & $(48)$ & 56 & $(52)$ \\
\hline Age, years, median (range) & \multicolumn{2}{|c|}{$65(36-76)$} & \multicolumn{2}{|c|}{$64(36-75)$} & \multicolumn{2}{|c|}{$66(38-76)$} \\
\hline \multicolumn{7}{|c|}{ Sex } \\
\hline Male & 81 & $(75)$ & 38 & (73) & 43 & $(77)$ \\
\hline Female & 27 & $(25)$ & 14 & (27) & 13 & $(23)$ \\
\hline \multicolumn{7}{|l|}{ Smoking status } \\
\hline Never & 11 & $(10)$ & 9 & $(17)$ & 2 & (4) \\
\hline Former & 27 & $(25)$ & 14 & (27) & 13 & (23) \\
\hline Current & 70 & (65) & 29 & (56) & 41 & (73) \\
\hline \multicolumn{7}{|l|}{ ECOG performance status } \\
\hline 0 & 46 & $(43)$ & 16 & (31) & 30 & $(54)$ \\
\hline 1 & 60 & $(56)$ & 34 & (65) & 26 & $(46)$ \\
\hline 2 & 2 & (2) & 2 & (4) & 0 & (0) \\
\hline \multicolumn{7}{|l|}{ Histology } \\
\hline $\mathrm{Ad}$ & 46 & $(43)$ & 18 & (35) & 28 & $(50)$ \\
\hline $\mathrm{Sq}$ & 38 & $(35)$ & 18 & (35) & 20 & $(36)$ \\
\hline NOS & 22 & $(20)$ & 15 & (28) & 7 & (12) \\
\hline $\mathrm{AdSq}$ & 2 & (2) & 1 & $(2)$ & 1 & (2) \\
\hline \multicolumn{7}{|l|}{ Clinical stage } \\
\hline IIIA & 44 & $(41)$ & 17 & (33) & 27 & $(48)$ \\
\hline IIIB & 64 & $(59)$ & 35 & $(67)$ & 29 & $(52)$ \\
\hline \multicolumn{7}{|l|}{ Mutational status } \\
\hline Wild type & 69 & $(62)$ & 30 & (57) & 39 & (70) \\
\hline ALK & 4 & (4) & 2 & (4) & 2 & (3) \\
\hline EGFR & 2 & (2) & 2 & (4) & 0 & (0) \\
\hline ROS1 & 1 & (1) & 0 & (0) & 1 & (2) \\
\hline Unknown & 32 & $(30)$ & 18 & (35) & 14 & (25) \\
\hline
\end{tabular}

ECOG, Eastern Cooperative Oncology Group; Ad, adenocarcinoma; Sq, squamous cell carcinoma; NOS, not otherwise specified; AdSq, adenosquamous carcinoma; ALK, 
anaplastic lymphoma kinase; EGFR, epidermal growth factor receptor.

Table 2. Treatment of patients with locally advanced non-small cell lung cancer $(n=108)$

\begin{tabular}{|c|c|c|}
\hline & \multicolumn{2}{|c|}{ All } \\
\hline & No. & $\%$ \\
\hline Duration of radiation, days, median (range) & \multicolumn{2}{|c|}{$43(4-68)$} \\
\hline Dose of radiation, Gy, median (range) & \multicolumn{2}{|c|}{$60(10-66)$} \\
\hline V20, \%, median (range*) & \multicolumn{2}{|c|}{$22(3-37)$} \\
\hline V5, \%, median (range*) & \multirow{2}{*}{\multicolumn{2}{|c|}{$\frac{33(5-54)}{12(2-19)}$}} \\
\hline Mean lung dose, Gy, median (range*) & & \\
\hline Regimen of chemotherapy & \multicolumn{2}{|c|}{$12(2-19)$} \\
\hline CDDPIVNR & 83 & (77) \\
\hline wCBDCA $\square T T X$ & 19 & (18) \\
\hline $\mathrm{CDDP} \square \mathrm{DOC}$ & 3 & (3) \\
\hline $\mathrm{CDDP} \square \mathrm{S}-1$ & 3 & (3) \\
\hline \multicolumn{3}{|l|}{ Cycles of chemotherapy } \\
\hline $1 / 2$ & $16 / 13$ & $(15 / 12)$ \\
\hline $3 / 4$ & $16 / 63$ & $(15 / 58)$ \\
\hline \multicolumn{3}{|l|}{ Chemotherapy after recurrence } \\
\hline Cytotoxic / ICI / TKI & $43 / 18 / 7$ & $(40 / 17 / 6)$ \\
\hline Radiation [brain] / OPE / BSC & $30[20] / 3 / 14$ & $(28[19] / 3 / 13)$ \\
\hline \multicolumn{3}{|l|}{ Number of regimens after recurrence } \\
\hline $0 / 1 / 2 / \geq 3$ & $27 / 32 / 14 / 9$ & $(25 / 30 / 13 / 8)$ \\
\hline
\end{tabular}

*Excluding 4 patients (2 with disease progression, 1 with tracheoesophageal fistula, and 1 with atelectasis).

CDDP, cisplatin; VNR, vinorelbine; wCBDCA, weekly carboplatin; PTX, paclitaxel; DOC, docetaxel; TKI, tyrosine kinase inhibitor; ICI, immune checkpoint inhibitor; OPE, operation; BSC, best supportive care. 
Table 3. Efficacy and safety of chemoradiotherapy in patients with locally advanced nonsmall cell lung cancer $(n=108)$

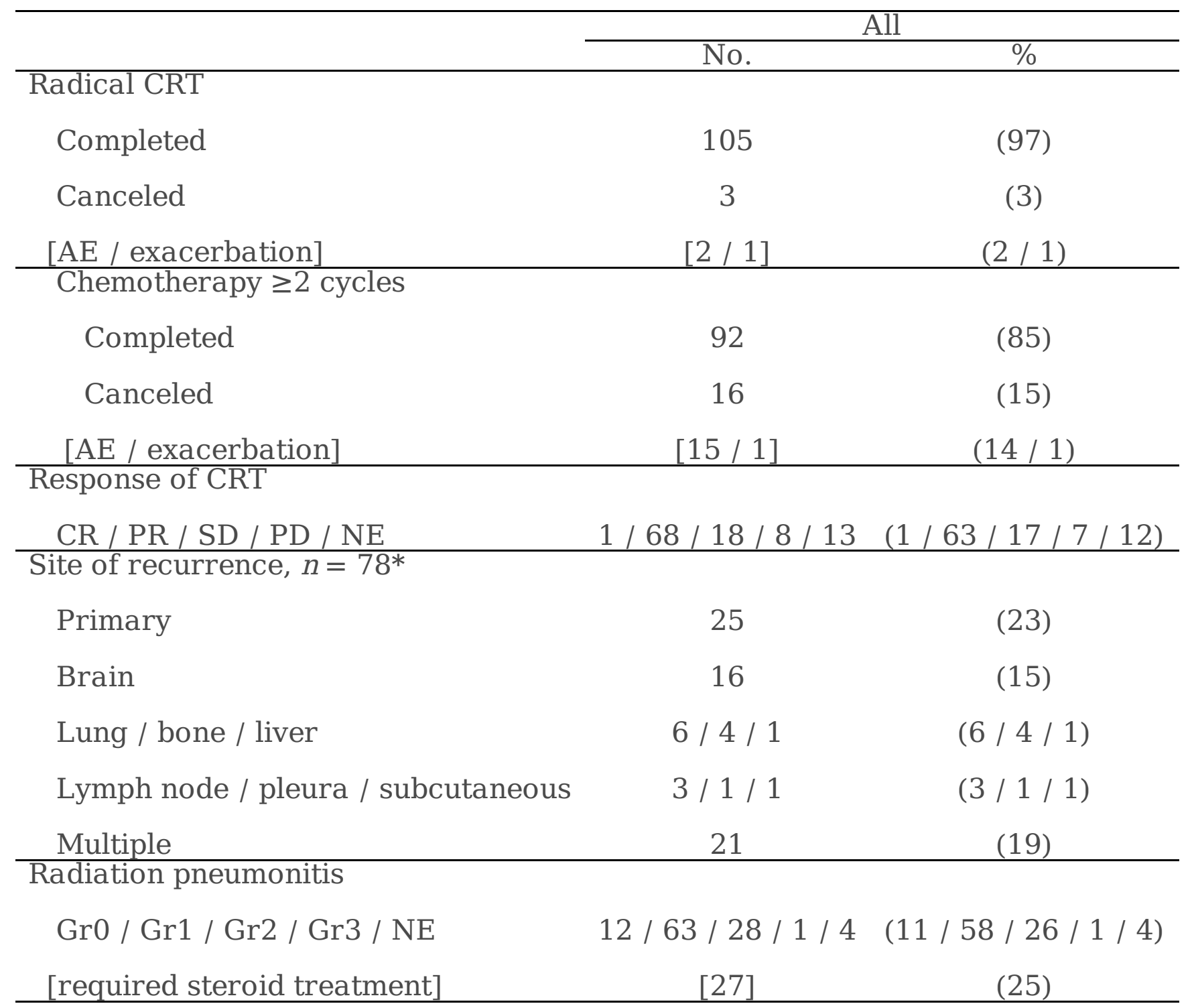

CRT, chemoradiotherapy; AE, adverse event; CR, complete response; PR, partial response; $\mathrm{SD}$, stable disease; $\mathrm{PD}$, progressive disease; Gr, grade; NE, not evaluated.

* Patients died without evaluation of recurrent sites $(n=4)$.

Table 4. Survival analyses of patients with locally advanced non-small cell lung cancer treated with chemoradiotherapy $(n=108)$ 


\begin{tabular}{lcccccc} 
& \multicolumn{3}{c}{ Univariate } & \multicolumn{2}{c}{ Multivariate } \\
\cline { 2 - 6 } & HR & $\mathbf{9 5 \%}$ CI & $\boldsymbol{P}$ & HR & $\mathbf{9 5 \%}$ CI & $\boldsymbol{P}$ \\
\hline $\begin{array}{l}\text { Age } \\
\geq 75 \text { vs. }<75 \text { years }\end{array}$ & 1.75 & $0.42-7.25$ & 0.44 & & & \\
\hline $\begin{array}{l}\text { Performance status } \\
\text { 2 vs. 0-1 }\end{array}$ & 10.25 & $2.26-46.46$ & 0.003 & 1.23 & $0.63-2.40$ & 0.54 \\
$\begin{array}{l}\text { Clinical stage } \\
\text { IIIB vs. IIIA }\end{array}$ & 1.10 & $0.59-2.05$ & 0.76 & & & \\
\hline $\begin{array}{l}\text { Histology } \\
\text { Sq vs. non-Sq }\end{array}$ & 1.36 & $0.73-2.53$ & 0.33 & & & \\
\hline $\begin{array}{l}\text { Driver mutations } \\
\text { EGFR/ALK/ROS1 (+) vs. (-) }\end{array}$ & 0.52 & $0.12-2.15$ & 0.36 & & & \\
\hline $\begin{array}{l}\text { Regimen of chemotherapy } \\
\text { CBDCA vs. CDDP }\end{array}$ & 0.98 & $0.43-2.15$ & 0.36 & & & \\
\hline $\begin{array}{l}\text { Cohort by treatment period } \\
\text { 2015-2018 vs. 2012-2015 }\end{array}$ & 0.50 & $0.25-0.99$ & 0.046 & 0.64 & $0.32-1.26$ & 0.20 \\
\hline $\begin{array}{l}\text { ICIs after recurrence } \\
\text { ICI (+) vs. (-) }\end{array}$ & 0.21 & $0.07-0.58$ & 0.003 & 0.20 & $0.07-0.57$ & 0.003 \\
\hline $\begin{array}{l}\text { PACIFIC criteria } \\
\text { Eligible vs. ineligible }\end{array}$ & 0.50 & $0.27-0.93$ & 0.028 & 0.51 & $0.26-1.01$ & 0.052 \\
\hline $\begin{array}{l}\text { Radiation pneumonitis } \\
\text { Grade 1-3 vs. Grade 0 }\end{array}$ & 0.39 & $0.16-0.94$ & 0.037 & 0.46 & $0.15-1.38$ & 0.16 \\
& & & & & & \\
\end{tabular}

HR, hazard ratio; CI, confidence interval; Sq, squamous cell carcinoma; EGFR, epidermal growth factor receptor; ALK, anaplastic lymphoma kinase; CBDCA, carboplatin; CDDP, cisplatin; ICI, immune checkpoint inhibitor.

\section{Figures}




\section{Figure 1.}

A

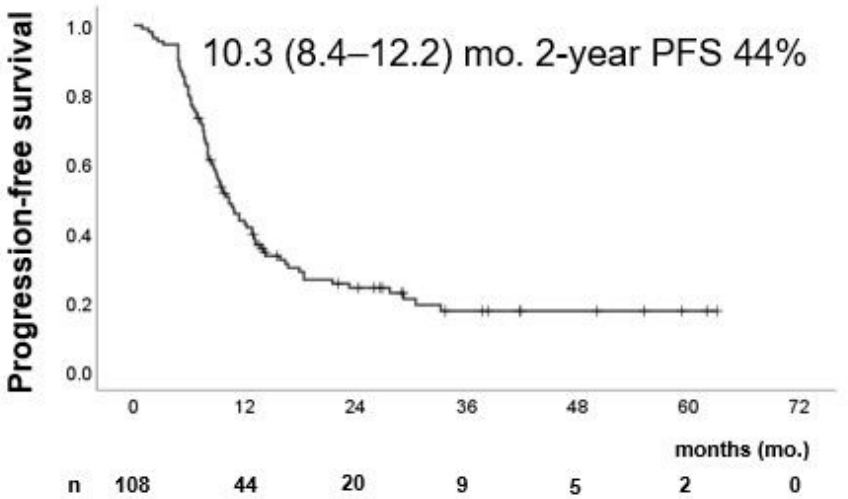

C $\quad$ 2015-2018 $(n=56)$ :

12.0 (7.3-16.7) mo. 2-year PFS 56\% 2012-2015 ( $n=52)$ :

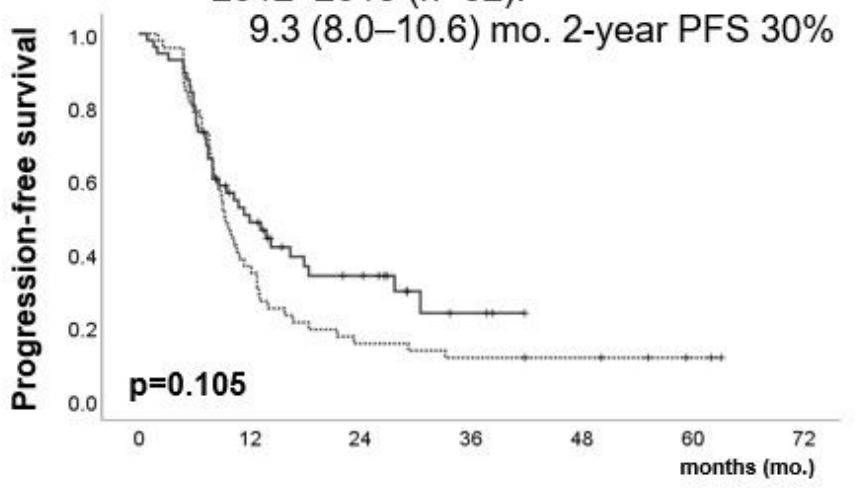

\section{B}

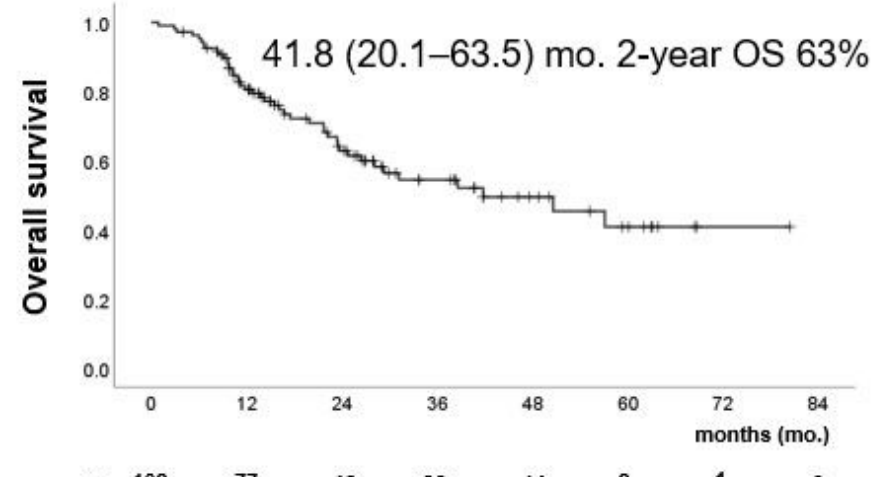

D - 2015-2018 ( $n=56)$ :

not available, 2-year OS $75 \%$ 2012-2015 $(n=52)$ :

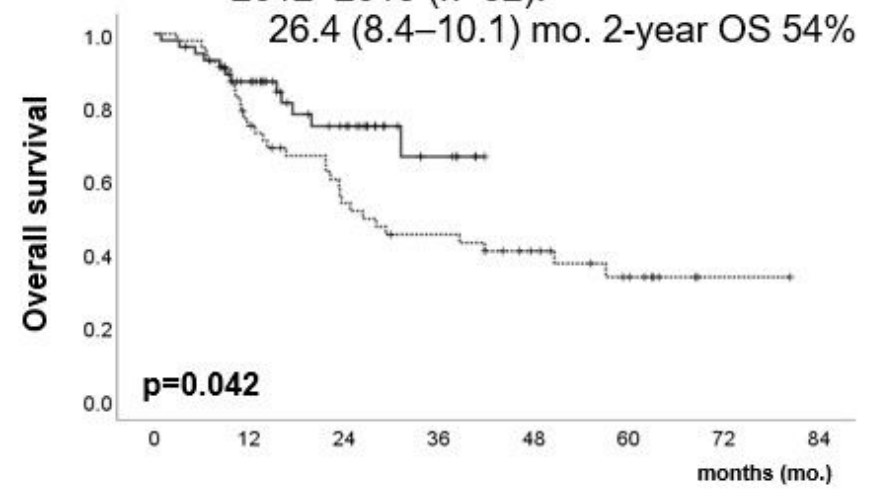

2015/7-2018/6

2012/1-2015/6

$\begin{array}{lccccccc}56 & 25 & 12 & 3 & 0 & 0 & 0 & 201 \\ 52 & 19 & 8 & 6 & 5 & 2 & 0 & 201\end{array}$

$2015 / 7-2018 / 6$

$\begin{array}{lllcclll}56 & 39 & 21 & 6 & 0 & 0 & 0 & 0 \\ 52 & 38 & 25 & 20 & 14 & 8 & 1 & 0\end{array}$

\section{Figure 1}

Kaplan-Meier analysis-based estimates of survival in patients with locally advanced non-small cell lung cancer (LA-NSCLC) treated with chemoradiotherapy based on the treatment periods $(n=108)$. A, B. Progression-free survival (PFS) and overall survival in all patients with LA-NSCLC in this study. C, D. Comparison of survival between patients treated from January 2012 to June 2015 ( $n=52$; broken line) and those treated from July 2015 to December $2018(n=56$; solid line). P values were determined using the log-rank test. Survival times in each group are indicated as medians ( $95 \%$ confidence interval) in months and the 2-year survival rate (\%). 
Figure 2.

A

- $\mathrm{ICl}(+)(\mathrm{n}=18):$

not available, 2-year OS $87 \%$

....... ICl $(-)(\mathrm{n}=64)$ :

$22.3(15.5-29.1)$ mo. 2-year OS $41 \%$

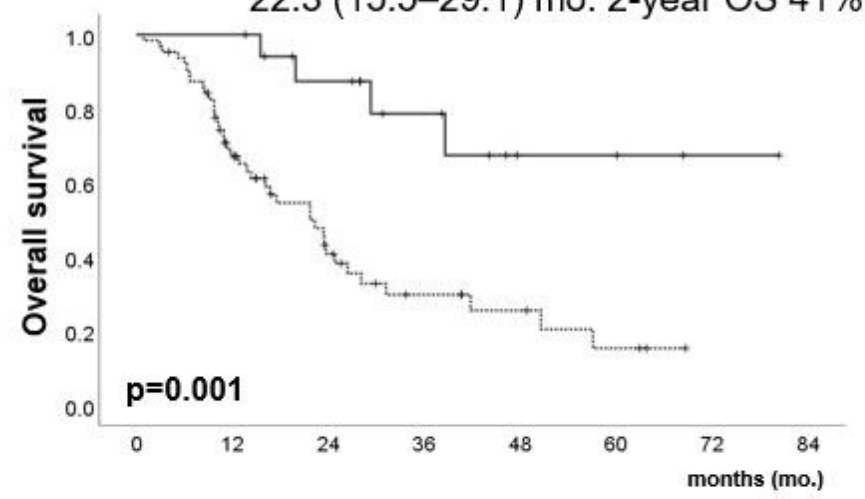

$\begin{array}{lllllllll}\mathrm{ICl}(+) & 18 & 18 & 13 & 8 & 3 & 3 & 1 & 0 \\ \mathrm{ICl}(-) & 64 & 37 & 17 & 9 & 6 & 3 & 0 & 0\end{array}$
B

- TKI $(+)(\mathrm{n}=7)$ :

50.6 (0.0-109.0) mo. 2-year OS 60\% ...... TKI $(-)(n=75)$ :

24.8 (16.8-32.8) mo. 2-year OS 51\%

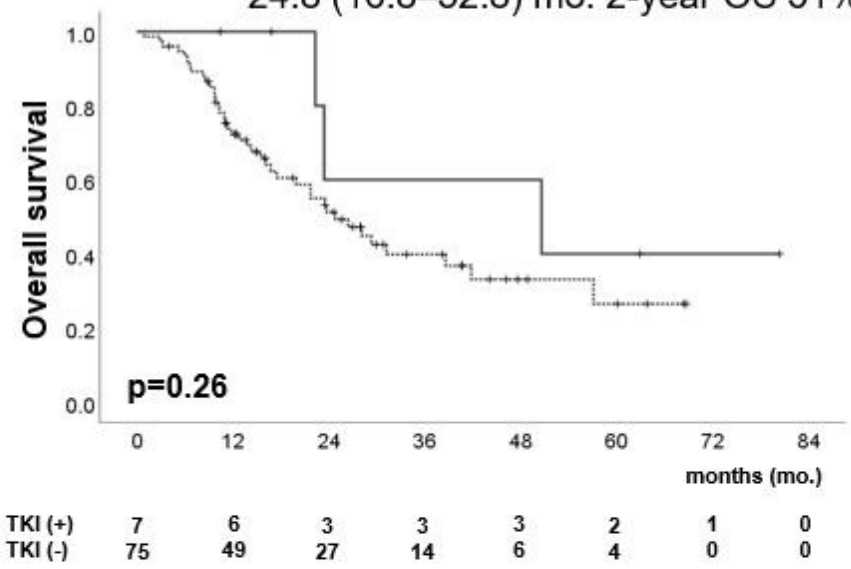

\section{Figure 2}

Comparison of overall survival in relapsed patients after chemoradiotherapy for locally advanced disease ( $n=82)$ A. Kaplan-Meier analysis-based estimates of survival of patients treated with an immune checkpoint inhibitor (ICl) (solid line) and those treated without an ICI (broken line). B. Kaplan-Meier analysis-based estimates of survival of patients treated with tyrosine kinase inhibitors (TKIs) targeted to EGFR, ALK, and ROS1 (solid line) and those treated without TKIs (broken line). P values were determined using the log-rank test. Survival times in each group are indicated as medians (95\% confidence interval) in months and the 2-year survival rate (\%). EGFR, epidermal growth factor receptor; ALK, anaplastic lymphoma kinase

\section{Supplementary Files}

This is a list of supplementary files associated with this preprint. Click to download.

- CRT2018SupplementalFiguresv1.0BMCCancer.pptx

- CRT2018SupplementalTablesv1.0BMCCancer.docx 